\title{
Insecurity for compact surfaces of positive genus: commentary
}

\author{
Victor Bangert • Eugene Gutkin
}

(C) The Author(s) 2011. This article is published with open access at Springerlink.com

The authors acknowledge that their Proposition 8.4 in [1] is not new. It has been proved and published earlier by Rafael Ruggiero. See Corollary 3.2 and the proof of Corollary 3.3 in [3], and also [2].

Open Access This article is distributed under the terms of the Creative Commons Attribution Noncommercial License which permits any noncommercial use, distribution, and reproduction in any medium, provided the original author(s) and source are credited.

\section{References}

1. Bangert, V., Gutkin, E.: Insecurity for compact surfaces of positive genus. Geom. Dedicata 146, 165-191 (2010)

2. Ruggiero, R.O.: On the creation of conjugate points. Math. Z. 208, 41-55 (1991)

3. Ruggiero, R.O.: On the generic nonexistence of rational geodesic foliations in the torus, Mather sets and Gromov hyperbolic spaces. Bol. Soc. Brasil. Mat. (N.S.) 31, 93-111 (2000)

This is a commentary to the articles doi:10.1007/s10711-009-9432-8, doi:10.1007/BF01377597, doi:10.1007/BF02571508.

\footnotetext{
V. Bangert

Mathematisches Institut, Albert-Ludwigs-Universität, Eckerstrasse 1, 79104 Freiburg im Breisgau, Germany

e-mail: bangert@email.mathematik.uni-freiburg.de

E. Gutkin $(\varangle)$

Nicolaus Copernicus University (UMK), Chopina 12/18, 87-100 Torun, Poland

e-mail: gutkin@mat.umk.pl

E. Gutkin

Institute of Mathematics of the Polish Academy of Sciences (IM PAN), Sniadeckich 8,

00-956 Warszawa, Poland

e-mail: gutkin@impan.pl
} 